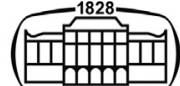

AKADÉMIAI KIADÓ

Pollack Periodica

An International Journal

for Engineering and Information Sciences

16 (2021) 1, 157-161

DOI:

$10.1556 / 606.2020 .00175$

(c) 2020 The Author(s)

\section{ORIGINAL RESEARCH}

\section{PAPER}

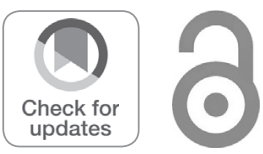

\title{
The potential of residential area - A practice design at Roissypole
}

\author{
Chang $\mathrm{Lu}^{1 *} \odot$, Honghao $\mathrm{He}^{1}$, Tianyu Zhao ${ }^{1}$, Agnes Borsos ${ }^{2}$ and \\ Janos Gyergyak ${ }^{3}$
}

\footnotetext{
${ }^{1}$ Marcel Breuer Doctoral School, Faculty of Engineering and Information Technology, University of Pécs, Boszorkány u. 2, H-7624 Pécs, Hungary

${ }^{2}$ Department of Interior, Applied and Creative Design, Faculty of Engineering and Information Technology, University of Pécs, Boszorkány u. 2, H-7624 Pécs, Hungary

${ }^{3}$ Department of Architecture and Urban Planning, Faculty of Engineering and Information Technology, University of Pécs, Boszorkány u. 2, H-7624 Pécs, Hungary
}

Received: December 31, 2019 • Revised manuscript received: June 13, 2020 • Accepted: September 11, 2020

Published online: February 5, 2021

\begin{abstract}
The Roissypole is a complex residential area within Charles de Gaulle airport in Paris. There are already accommodations of different levels with bars, cafes and more in this area, but there is a lack of simple connection between existing buildings, which help brings life to the outside atmosphere. The proposed concept is not a simple public facility renew instead of a new social and functional design, which is to reinvent the airport region design to transform the Roissypole district into an appealing enjoyable and lively living environment. While enhancing the life quality for both long and short-term residents, for people to share their life, live in an active way, it also provides passive life and initiative social activities, which form a new lifestyle.
\end{abstract}

\section{KEYWORDS}

airport surrounding, public space activation, communication, social, landscape

\section{INTRODUCTION}

The area Roissypole at Paris-Charles de Gaulle Airport (CDG) in France received a chance to improve its environmental quality with a competition. The research team includes doctoral students in different research fields and backgrounds in order to reach a multi-dimensional balance in the design process and the result. Architectural design, landscape design and neighborhood design are involved in the research.

The indicated area of Roissypole covers an area of 17.7 ha. It is located in between Terminal 1, 2 and 3 of CDG, at the Réseau Express Régional (RER) railway station: Roissypole, and surrounded by driving lanes. Thus, Roissypole owns a high value in regard to both travelers' flow and staff's flow. The area is currently equipped with airport hotels, academy buildings, offices and shopping malls, meanwhile, there are two major open spaces close to the RER station in the center, and along with the station; they form the axis of Roissypole (Fig. 1). The observed fact is that the indicated area has already a public space system, but due to the large potential of traffic and flow, the public spaces need to be thoroughly upgraded and bear the responsibility of bringing up its neighborhood.

Public spaces, in either the nowadays world or in history, act efficient and important role of concentrating people's flow and activities [1]. Especially, when Roissypole occupies an essential place in CDG area, as mentioned above, the quality of its inherited open spaces determines directly the quality of the entire area.

From landscape point of view, the landscape of the Charles de Gaulle Airport administrative area and other areas is mainly to serve the surrounding users. But the surrounding buildings and functions are constantly upgrading and changing, and people's travel patterns 


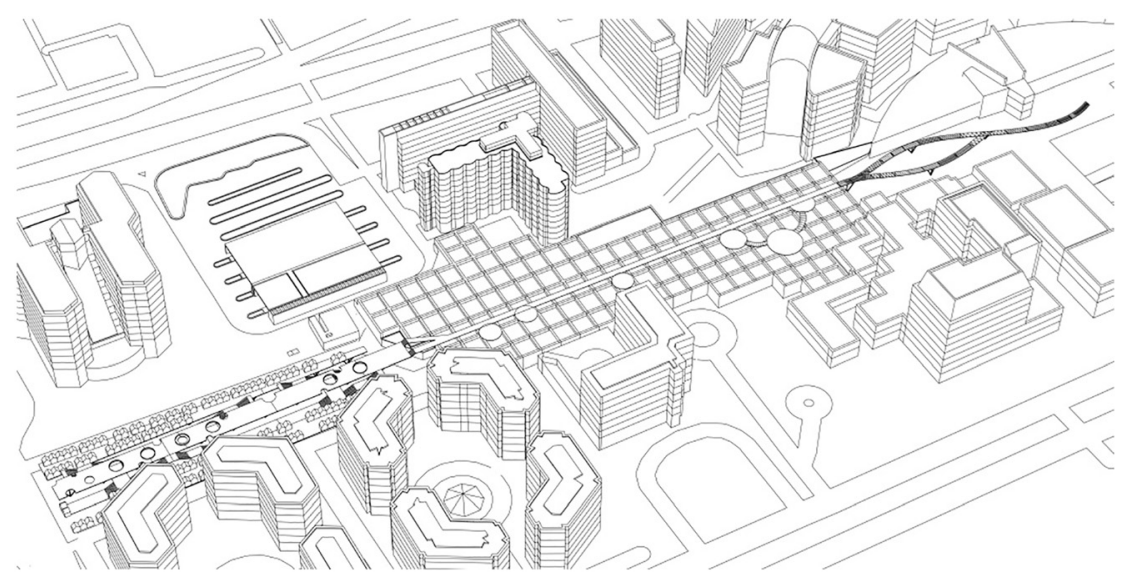

Fig. 1. Functioning and axis analysis of Roissypole

and habits are also changing. So, the current landscape needs to reconsider the upgrade and design to meet the current use needs and future development requirements.

\section{PROBLEM SHOOTING STUDIES}

\subsection{The area of Roissypole measured and studied with the following methods}

- Modeling the indicated zone with existing buildings and built environment in computer software (Sketchup pro and ArchiCAD 22). The model was helpful to understand the built situation from diverse perspectives;

- Mapping the area due to different indicators. Maps include the inherent functions, size and position of existing open spaces, the height of existing buildings, current public traffic flow, etc. They provide easier access to the problems behind and direct approaches to the possible solutions;

- Study of related flights. This part of the study was helpful to understand the potential users, the time they may spend at Roissypole and for what purpose;

- Building height evaluation. Sections of the area can be constructed then, and therefore the optimal solution can be defined;

- Study of open space and enclosed zone. With the existing border of open space and enclosed zone, it is possible to evaluate if the current ratio of the open-enclosed area shall be balanced;

- User study. The user consists of travelers and staff, but the user study provides a clear goal of what the design is supposed to serve;

- Greenery study. To locate the status of current green area, which is an essential component and enhancing feature of public space;

- Connectivity study. Through the connectivity study, the existing traffic junctions of vehicles and pedestrian, public and staff can be studied. It serves the later optimizing work in the design as well;
- Orientation and view study. Due to the general human preference [2], it is critical to understand the site orientation and the optimal view perspective of users.

\subsection{What can be indicated through the studies above?}

- Roissypole is an area with various dimensions regarding buildings' height. The existing buildings have a height ranging from two stories to tens. This may provide wider concepts for the public space, towards the vertical dimension;

- The most required public pedestrian connections are between the railway station and different destinations. The destinations include the Terminal 3, two hotels located to the North of the station and the shopping mall to the North-East. Meanwhile staff may have access and enjoy the connections as well. Parallel, the currently broken situation along the East-West axis, by the railway station, can be a point to break through. The reasons are that

1. The new public space requires large space and the existing greenery on the west half of the indicated zone is not adequate for diverse activities for both staff and travelers;

2. Obvious emptiness was found at each side of the station along the axis, so the connectivity could very likely awake both areas.

- Greenery exists, but in low quality and inadequate. Besides the trees appear occasionally around the buildings, especially the hotels, shadings provided by vegetation are hard to find;

- There are already accommodations of different levels with the shopping mall, bars, cafe, landscape and more, but people only stay in the hotels instead of going outside. Therefore, it is found that there might be a lack of a simple way to connect existing buildings and bring people to the outside atmosphere. Further on, there come 2 problems for us to solve: communication efficient, and loneliness. Loneliness has become a globalizing problem. 
2018, Claudia Hammond reveals the results of the BBC Loneliness Experiment that is 55,000 people took part in this experiment making it is the largest survey of its kind in the world. The survey shows that loneliness can affect people of all ages. $40 \%$ of 16 to 24 -year-olds who took part in the survey they often or very often feel lonely. Prof. Pamela Qualter from the University of Manchester, Prof. Christina Victor from Brunel University London and Prof. Manuela Barreto from the University of Exeter conducted the research. There are a number of possible reasons why young people reported the highest levels of loneliness in the survey. One of the reasons is young people who feel lonely have more online-only friends and they spend more time chatting with them who do not overlap with their real-life friends. People who are high levels of loneliness use social media more often than other people. It is understandable that young people who are stuck on the internet instead of social in real life [3];

- At present, the old landscape planning method is single, and the connection between landscape areas with different functions is the transportation hub space. The transportation hub is a transition space for tourists to enter the landscape area, and it is also a functional space to evacuate the pedestrian flow at the airport. The use area and function of the business landscape area on the northeast side cannot meet the requirements of current users. At present, the users are basically related staff at the airport. The current landscape does not provide a space suitable for users to stop talking and relax, and due to the division of the transportation hub, there is not much connection between the two landscape areas. There are more users in the landscape on the southwest side, mainly tourists who live in hotels around the airport. They will walk through this landscape area to reach their hotels. But a single landscape does not attract pedestrians on foot and lacks space to stay. At the same time, the landscape has not brought added value to the surrounding hotels, nor can it provide a beautiful transition space for travelers.

\subsection{Conclusion based on the problems found}

Public space as an important part of the Roissypole district provides people with daily life and social use. Through the development of this area's public space, it is expected that the communication of different people, interpersonal, belongingness and the perception of the local atmosphere can be improved.

The landscape area has a close impact on the surrounding different functional areas. It is an important public place connecting offices, hotels, residences, education, commerce and transportation, etc. It is not only a place for leisure gathering, but also can effectively guide passengers to other functional spaces and increase the connection between different functional areas [4].

The current landscape needs to solve:

1. How to increase the vitality of the old landscape through landscape redesign so that tourists and other users can stop;
2. How to attract people to perform activities in the landscape space and stimulate the commercial value of the place;

3. How to connect the landscape space with different functions, so that the landscape space can be extended and the quality improved.

Base on the result and findings of the studies, the main concept come to the team's mind with three major perspectives: user, connection and experience. The teams planned to solve them with human perspective architecture and landscape.

\section{CONCEPT}

Base on the result and findings of the studies, the main concept come to the team's mind with three major perspectives: user, connection and experience. To solve them with human perspective architecture and landscape were proposed.

The social life in public spaces contributes fundamentally to the quality of life of individuals and society as a whole [5]. Active participation can be used to promote the sense of ownership and maximize satisfaction [6]. The ideal state of public space is unconstrained, stimulating user participation and free interaction; spatial properties subtly guide people's behavior there. The people gathering in the Roissypole district should get more social possibilities, but social activities are not easily accessible. So, a new connection to make this public space strong and inclusive was created, and all kinds of temporary activities will be carried out in that public space, they will help in creating a cohesive and sustainable community with strong relations. The specified goals to reach are [7]:

- Connection between the blank spaces on both sides of the railway station. It is meantime the longitudinal axis of the entire area;

- Activate the atmosphere with more people and activities;

- Improve visual quality of the area and make the atmosphere human-philic.

\subsection{What do the above three points mean to the architectural approach of the design concept}

3.1.1. The bridge. A physical bridge is necessary along the axis of Roissypole, because the length of the bridge can be enriched with functions regarding various aspects, for instance commercial, cultural and leisure sports.

3.1.2. Concept of creating a market. Market becomes an important intermediate tool, which is able to involve wide range of sale content and gather customers. And an active public space can be expected. Several types of markets have been taken into account, for instance, indoor markets with outdoor spaces in between, shopping colonnades and wide market halls. Considering the visual quality that users can 
see through without obstacles, indoor masses are abandoned. Chalets and the form of Christmas market were selected, because of its warm welcoming and that people can walk through and see through.

3.1.3. Three branches and the chalets. To prolong the bridge crossing the railway station that connects the two existing open spaces was decided, elongate it to the West side, and therefore create a multi-story public space. Spread three branches with different heights to enrich users' view, enhance the playfulness, and ease users' vertical movement (Fig. 2). Chalets are placed on both sides of the three branches, with a rhythm.

3.1.4. Sub free spaces. Fragmented meeting points amongst the planned public area are decided to be linked by straight pedestrian ways. To develop the landscape and greenery in vertical dimension, voids are placed along the middle of the pedestrian ways with resting area around. This composition contributes to a clear visual experience for users when they are using the public place, in other words, the market. Railings along the edges of the branches and the bridge are designed to host consumers with some food or drink, or talking only.

3.1.5. Sport function. Towards the East open space, a jogging ramp is connected to the East end of the bridge, and reaches the ground with easy slope. Our team designed the jogging ramp because leisure sports help both long-term and short-term users to meet and socialize with healthy exercise.

\subsection{What do the above three points mean to the landscape approach of the design concept}

3.2.1. One center and two areas. By adding a new sky corridor design, the landscape area is connected and at the same time it is a transition space between two landscapes with different functions. Through the newly added sky corridor design, the landscape area is connected, and it is also a transition space between two landscapes with different functions. The landscape on the northeast side is mainly for business and office use. Through the air corridor, it gradually transitions into a landscape mainly for commercial activities, and also makes the two landscapes closer.

3.2.2. Increase business space. The redesign of the landscape on the South-West side is the focus of the transformation throughout the project. First, by analyzing the background color relationship between the surrounding building blocks and the street, a new path and landscape block are designed based on the texture between the analysis plots. On the basis of re-planning, add a second-floor public space, and then use the container as a standard unit of commercial space. Increasing commercial space can attract people to come to spend and stop. In this way, landscape space can be used to create economic value. It also adds different leisure consumption space to the surrounding space and enriches commercial diversity.

3.2.3. Business leisure space. In addition to providing convenient and comfortable business hotel services for transit tourists, the functional area around the airport also provides a place for daily busy staff to rest and communicate. In the landscape re-planning plan, seats and gathering communication spaces were added. The distribution of the seats is arranged according to the gathering habits of the office crowd and the direction of the sun. At the same time, the elements of water are added to the landscape to enrich the elements of the landscape and increase the landscape experience in order to create a more comfortable and communication gathering place for the daily office crowd.

3.2.4. Adding landscape nodes. In order to make the landscape node produce a rhythm change, the landscape trail from the commercial landscape space to the commercial landscape space spans the transportation hub space. Add nodes on the roof of the transportation hub to form a landscape corridor and ornamental platform on the roof. A new traffic line is formed, and the entire landscape walkway has a rhythm change from low to high. It is also the best leisure platform to create a scenic sight. The main role of the spatial distribution of nodes in commercial landscape space is to increase the interest of the landscape and create more spaces for leisure gathering. Let passengers have a space to stay while walking, increase the opportunity for

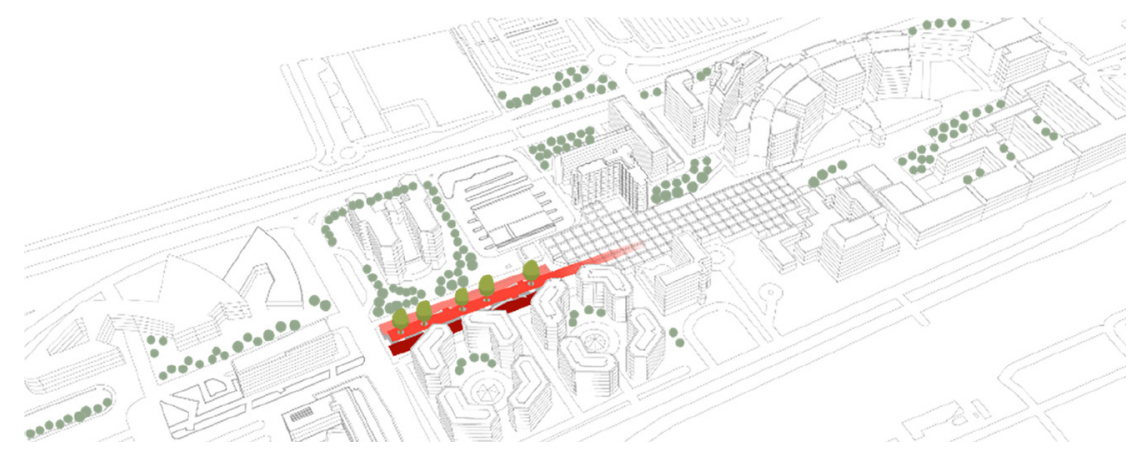

Fig. 2. Greenery plan and concept of market branches of the bridge 


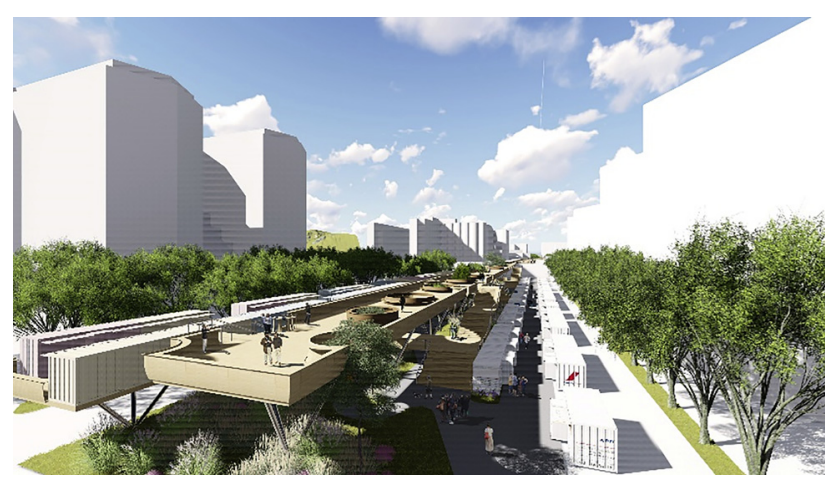

Fig. 3. Rendering of the concept design from the South-West perspective

consumption, and also feel the changes in the rhythm of the surrounding landscape design (Fig. 3).

\section{CONCLUSION}

The commercial and mild sport functions to the designated area in Roissypole to activate the atmosphere were applied. Market zone and jogging ramp make up a chain to attract people, invite them to move around and meet.

The connection between two sides of the axis is realized by a bridge above the railway station, between the market zone and jogging ramp, and attached with few meeting terraces. The terraces are all set to be on the South-East side of the bridge, to make maximum use of the view while avoid blocking the utilities of the existing station building.

By creating a multi-level and multi-functional public space the proposed concept intends to attract staff and tourists to visit and spend some time here. And introducing market and rest area bridge in the designated area of Roissypole that nudge people physically closer together and to create more possibility for them oral communication.
Enriching public spaces will not banish loneliness from this area, but it could help by making staff and tourists feel more engaged and comfortable with their feeling.

Roissypole is a representative of airport attaching zone due to its traffic, user flow and function characteristics. Therefore, the concepts applied to activate Roissypole are expected to provide inspiration for similar public space improvements in the following aspects:

1. Market as fundamental stimulation;

2. Physical connection between spaces of different characters;

3. Integrate leisure sport as health ingredient.

\section{REFERENCES}

[1] P. Moelsae, "Public space - urban spaces of multiple and diverse publics," MSc Thesis, City University of New York, 2014.

[2] C. Montgomery, Happy City: Transforming Our Lives through Urban Design. Farrar, Straus and Giroux, US, 2013.

[3] C. Hammond, Who feels lonely? The results of the world's largest loneliness study, BBC Radio 4', All in the mind, 2018. [Online]. Available: https://www.bbc.co.uk/programmes/articles/2yzhfv4 DvqVp5nZyxBD8G23/who-feels-lonely-the-results-of-the-world-slargest-loneliness-study. Accessed: Dec. 20, 2019.

[4] P. Sendra, "Rethinking urban public space, Assemblage thinking and the uses of disorder," J. City, vol. 19, no. 6, pp. 820-836, 2015.

[5] W. H. Whyte, The Social Life of Small Urban Space. Assemblage thinking and the uses of disorder conservation foundation, Project for Public Spaces, NY, 1980.

[6] Sz. Portschy, "Community participation in sustainable urban growth, Case study of Almere, The Netherlands," Pollack Period., vol. 11, no. 1, pp. 145-155, 2016.

[7] R. Basha, "Barrier-free park in Prizren - visioning workshop involving persons with disability and the elderly," Pollack Period., vol. 13, no. 2, pp. 237-248, 2018. 